\title{
Sex work, discrimination, drug use and violence: a pattern for HIV risk among transgender sex workers compared to MSM sex workers and other MSM in Guatemala
}

\author{
William M. Miller (D) ${ }^{a}$, William C. Miller ${ }^{a, b}$, Clare Barrington ${ }^{c, d}$, Sharon S. Weir ${ }^{a, d}$, Sanny \\ Y. Chen ${ }^{\mathrm{e}}$, Michael E. Emch ${ }^{\mathrm{a}, \mathrm{d}, \mathrm{f}}$, Audrey E. Pettifor ${ }^{\mathrm{a}, \mathrm{d}}$ and Gabriela Paz-Bailey ${ }^{\mathrm{g}}$
}

${ }^{a}$ Department of Epidemiology, Gillings School of Global Public Health, University of North Carolina at Chapel Hill, Chapel Hill, NC, USA; ${ }^{\mathrm{b}}$ Division of Infectious Diseases, Department of Medicine, University of North Carolina at Chapel Hill, Chapel Hill, NC, USA; 'Department of Health Behavior, Gillings School of Global Public Health, University of North Carolina at Chapel Hill, Chapel Hill, NC, USA; ${ }^{\mathrm{d}}$ Carolina Population Center, University of North Carolina at Chapel Hill, Chapel Hill, NC, USA; ${ }^{e}$ Division of Global HIV/AIDS, Centers for Disease Control and Prevention - Central America Regional Office, Guatemala City, Guatemala; ${ }^{f}$ Department of Geography, University of North Carolina at Chapel Hill, Chapel Hill, NC, USA; ${ }^{9}$ Training Programs in Epidemiology and Public Health Interventions Network (TEPHINET)

Central American office, Guatemala City, Guatemala

\begin{abstract}
The risk of HIV infection is higher among transgender women and cisgender men who have sex with men (MSM) compared to the general population due in part to social and contextual factors. This study aimed to determine the prevalence and association of alcohol and drug abuse, discrimination and violence among transgender sex workers compared to cisgender male sex workers and cisgender men who had not received money for sex in Guatemala City. In 2010, transgender women and cisgender men who had had sex with men or transgender women were recruited into a cross-sectional behavioural survey. Among transgender women, $86 \%$ received money for sex in the past year. Transgender sex workers were more likely to use drugs and binge drink, three times as likely to be discriminated against and eight times as likely to be forced to have sex compared to non-sex worker men. Male sex workers were twice as likely to use illicit drugs or experience physical violence and six times as likely to experience forced sex compared to non-sex worker men. Transgender and male sex workers would benefit from harm reduction for substance use, violence prevention, response and strategies to mitigate discrimination.
\end{abstract}

\section{ARTICLE HISTORY}

Received 11 October 2018

Accepted 21 August 2019

\section{KEYWORDS}

Transgender Persons; MSM; HIV; gender-based violence

\section{Introduction}

Male-to-female transgender women and cisgender men who have sex with men (MSM) or transgender women are disproportionately affected by HIV and other sexually transmitted infections (STI) worldwide (Beyrer et al., 2012; Poteat, Reisner, \& Radix, 2014). The HIV prevalence among transgender women in Latin American countries varies from 19\% in El Salvador to $34 \%$ in Argentina (Baral et al., 2013; Baral, Sifakis, Cleghorn, \& Beyrer, 2007). Globally, the prevalence of HIV among transgender women who exchange money for sex is approximately two times the prevalence both among transgender women who do not engage in sex work and cisgender male sex workers, most of whom are also MSM (Operario, Soma, \& Underhill, 2008). The use of illicit drugs such 
as marijuana, methamphetamines, cocaine and alcohol abuse is more prevalent among transgender women than MSM (Barrington, Wejnert, Guardado, Nieto, \& Bailey, 2012). Among transgender women substance abuse has been associated with unprotected sexual intercourse and HIV infection (Reback \& Fletcher, 2014; Santos et al., 2014).

In 2013, the prevalence of HIV among transgender women in Guatemala City, regardless of engagement in sex work, was $24 \%$ as compared to $9 \%$ among MSM and $0.7 \%$ among the general population (Morales-Miranda et al., 2013). The prevalence of active syphilis was $6 \%$ among transgender women compared to $1 \%$ among MSM as per the same 2013 study. Transgender women, unlike other people at increased risk of HIV acquisition, cannot easily hide their minority status and therefore are subject to stigma and discrimination based on gender identity and community factors such as peer pressure and substance use, all factors which lead to increased engagement in sex work and decreased condom use (Baggaley, White, \& Boily, 2010; Baral, Logie, Grosso, Wirtz, \& Beyrer, 2013; Barrington, Galindo Arandi, Aguilar-Martínez, \& Miller, 2018; Bauer, Travers, Scanlon, \& Coleman, 2012; Beyrer et al., 2012; Clements-Nolle, Marx, Guzman, \& Katz, 2001; Guadamuz et al., 2011; Mansergh et al., 2006; Nuttbrock et al., 2009; Prestage et al., 2009; Wong, Chaw, Kent, \& Klausner, 2005). Transgender women are also at increased risk of anxiety and depression, often caused by rejection by family and friends, which can act as barriers to healthy sexual behaviour, heath-seeking behaviour, participation in education and the formal labour market potentially exacerbating transgender women's exclusion from society (Barrington, Acevedo, Donastorg, Perez, \& Kerrigan, 2017; Bockting, Robinson, \& Rosser, 1998; Dean et al., 2000; Koken, Bimbi, \& Parsons, 2009; Melendez \& Pinto, 2007; Nemoto, Operario, Keatley, Han, \& Soma, 2004; Stieglitz, 2010).

The synergy of sex work, social and behavioural factors is the basis of HIV risk among transgender women in Guatemala and Latin America (Barrington et al., 2018). Gender discrimination and transphobia affect educational and employment opportunities for transgender women in the region leading to the exchange of money or goods for sex (Aguilar Martinez \& Martinez, 2010; Boyce, Barrington, Bolanos, Arandi, \& Paz-Bailey, 2012). The combination of sex work and strong societal discrimination often leads to abuse and violence towards transgender women which negatively affects general health and increases their risk of acquiring or transmitting HIV (Aguilar Martinez \& Martinez, 2010; Garofalo, Herrick, Mustanski, \& Donenberg, 2007; Kenagy, 2005; Lombardi, Wilchins, Priesing, \& Malouf, 2001; Nemoto, Sausa, Operario, \& Keatley, 2006). Stigma and discrimination towards transgender women are underlying determinants that indirectly increase HIV risk in addition to causing deleterious effects on mental health and suicidal inclination (Bith-Melander et al., 2010; Clements-Nolle et al., 2001; Clements-Nolle, Marx, \& Katz, 2006; Garofalo, Osmer, Sullivan, Doll, \& Harper, 2006; Nuttbrock et al., 2013). Cisgender men (sex worker or not) also experience heightened risk of HIV given the biological risk from anal sex, a sexual network that includes transgender women, potential for unprotected sex and contextual factors such as criminalisation of sex work and same-sex behaviour (Baral et al., 2015). HIV-related stigma interacts and builds on societal judgment of certain behaviours, lifestyles or characteristics as undesirable or 'wrong,' including homosexuality, bisexuality and sex work (Parker \& Aggleton, 2003).

While neither same-sex behaviour nor sex work is criminalised in Guatemala, transgender women are often labelled as and perceived to be gay men, due to society's conflation of gender identity and sexual orientation, and experience physical and verbal abuse, sexual abuse, and discrimination during childhood and adulthood, a reality only made worse by the fact that many transgender women are not aware of their rights or do not believe in the governmental institutions whose mission is to protect the rights of the population (Aguilar Martinez, Castillo, de Ramirez, \& Reynoso, 2010; Amnesty International, 2001; Galindo Arandi, 2010).

In Central America, specifically, but in countries worldwide, transgender women have been recruited with MSM in surveillance studies and prevention programmes (Pollock, Silva-Santisteban, Sevelius, \& Salazar, 2016). Global guidance on surveillance (Joint United Nations Programme on HIV/AIDS (UNAIDS) and World Health Organization (WHO), 2011), monitoring and evaluation 
of the HIV epidemic ((UNAIDS), 2008) published prior to 2011 did not consider transgender women as separate population from MSM, further conflating sexual orientation and gender identity. In 2011, guidelines on prevention and treatment of HIV and other STI among MSM and transgender people gave brief mention to specific sexual health needs of transgender people that may be distinct from those of MSM (World Health Organization (WHO), 2011), in 2014 guidelines included separate sections on the needs of transgender people and in 2015(World Health Organization (WHO), 2015) and 2017 surveillance guidelines (WHO, CDC, UNAIDS, \& FHI 2017) recommended reporting data disaggregated for transgender people. Conducting stratified analyses by gender identity, sexual orientation and engagement in sex work can help users of surveillance and programme data to understand how the needs of transgender women and cisgender MSM sex workers are unique or similar to those of cisgender MSM who do not sell sex (Tucker, Arandi, Bolanos, Paz-Bailey, \& Barrington, 2014).

Although the disproportionate burden of HIV infection among transgender women is well-documented, further understanding of the determinants behind transgender women's high risk in Guatemala is lacking. The objective of this study was to determine the prevalence and association of alcohol and drug abuse, discrimination and violence among transgender women who receive money for sex as compared to cisgender MSM sex workers and cisgender MSM who do not exchange money for sex in Guatemala City.

\section{Materials and methods}

Transgender women and cisgender MSM (including those who reported sex with men and transgender women) were recruited into two cross-sectional surveys, one using respondent driven sampling (RDS) and the other time location sampling (TLS) in Guatemala City from September to December, 2010. Transgender women and cisgender men were eligible to participate if they were at least 18 years of age, resided in Guatemala City at the time of interview, reported sex with a man or transgender woman in the past 12 months and consented to participate in the study. Data collection procedures not described here were described previously (Paz-Bailey et al., 2013). For the RDS arm, 6 initial and 2 additional seeds with diverse socio-demographic, sexual orientation and gender identity profiles and who had large social networks were selected with guidance from local NGOs. Each participant was given 2 coupons to recruit cisgender men who have sex with men or transgender women they had seen or talked to in the past 30 days. Participants were enrolled at a single study site located at an NGO that provided primary care and HIV prevention and treatment services to the general population and had specialised services for transgender women, MSM and female sex workers. Interviews were conducted face-to-face by a trained interviewer in a private room. No personal identifiers were collected from participants in either arm. Participants received a primary incentive valued at 6 U.S. Dollars (USD) and secondary incentives valued at 4 USD for each eligible recruit who enrolled.

In the TLS arm, 40 venues were randomly selected without replacement each month for two months and one 4-hour venue-day-time unit was selected randomly for each venue. Replacement venue-day-time units were selected for each primary venue-day-time event and used when sampling could not be conducted at the original venue. Venues were selected from 54 eligible venues identified during the formative research. Eligible venues were estimated to yield at least 7 eligible men or transgender women during the 4-hour sampling event, deemed safe by study staff and where the site manager or owner granted permission to conduct the survey. At each recruitment venue, interviewers approached men and visually recognisable transgender women using a random interval, provided information about the study, applied a screening questionnaire to determine eligibility, requested written informed consent, administered the behavioural questionnaire using a handheld computer and distributed educational materials and the primary incentive worth USD 6. Interviewers found a quiet spot away from other people to conduct the interview in a way that would protect the participant's privacy and confidentiality. 
All participants provided written informed consent for the behavioural survey. The study was approved by the U.S. Centers for Disease Control and Prevention's Global AIDS Program Associate Director for Science Office, the Del Valle University of Guatemala and the University of North Carolina at Chapel Hill's institutional review board.

\section{Measures}

Trained field staff interviewed all eligible participants who provided written consent using a standardised questionnaire (Creswell et al., 2012; Kim et al., 2013). Questions covered sociodemographic characteristics, sexual history, drug use, alcohol use, discrimination and other adverse life events.

Outcomes measures included binge drinking defined as consuming 4 or more alcoholic beverages during one sitting in the past seven days; use of illicit drugs defined as having smoked marijuana or crack, snorting cocaine, inhaling glue, a solvent or poppers, injecting cocaine or heroin, taking ecstasy, non-prescription diazepam, amphetamines or another illicit drug in the past 12 months. Four additional outcomes categorised broadly as adverse life events were considered: (1) overarching experience with discrimination due to sexual orientation or gender identity, measured using the question, 'In the past 12 months, have you been discriminated or stigmatised because of your sexual orientation? By discrimination, we mean hitting, punching, kicking, threatening, nagging, scolding, or humiliating'; (2) a specific variable on experiencing physical violence, defined as having been hit, punched or kicked in the past 12 months because of the participant's sexual orientation or gender identity; (3) forced sex, measured with the question, 'Did someone in your life ever force you to have sex even though you did not want to?'; and (4) discrimination by family due to participants' sexual orientation or gender identity, measured through the question, 'Has anyone in your family ever shown you contempt or rejection because of your sexual orientation?'

The exposure variable was constructed from questions on sexual orientation, gender identity and recent history of sex work. Transgender sex workers identified as transgender, transvestite or transsexual (hereafter referred to as transgender) through the question, 'Among men who have sex with men are those who identify as gay, bisexual, heterosexual, or transgender/transsexual/transvestite. How do you identify yourself?' and responded affirmatively to having received money in exchange for sex in the past 12 months. While standard practice at the time, the question on gender identity conflates gender identity and sexual orientation and by current standards could be considered misgendering of transgender women by referring to them as men who hold a transgender identity. Participants who identified as gay, bisexual or heterosexual were assumed to identify with the male gender, hereafter referred to as cisgender men. Among cisgender men, categories were created for sex workers and non-sex workers based on the question on receiving money for sex in the past 12 months.

Ideally, we would have made transgender women who did not engage in sex work a reference group. However, the sample from this population was too small $(n=20)$ leading us to exclude those few participants from the analysis rather than group them with the cisgender non-sex workers or transgender sex workers. As part of the decision on how to categorise transgender non-sex workers we looked at their lifetime history of sex work. Half of the transgender women who had not received money for sex in the past year had engaged in sex work at some point in their lives. Hence, we concluded that transgender women who had not practiced sex work in the past year were dissimilar to their male counterparts but had not recently engaged in sex work and could not be defined as transgender women sex workers.

\section{Statistical analysis}

Participants recruited through RDS and TLS were combined to maximise the size of the transgender and cisgender populations. The analyses were carried out without weighting the sample for the probability of selection, as different methods exist for weighting RDS and TLS data. Surveys from 
participants in RDS and TLS arms that had already participated in the other arm were excluded $(n=$ 38). Transgender women who did not receive money for sex in the past 12 months were excluded from the analyses due to the small sample size $(n=20)$.

Bivariable analyses were conducted using ANOVA for a difference in means, Kruskal-Wallis test for difference in medians and Cochran-Mantel-Haenszel general association test for difference in proportions. Bivariable and multivariable log binomial models were used to calculate prevalence and prevalence ratios (PR) for each outcome mentioned above. Due to the small number of events for the physical abuse outcome, we used a Poisson model with robust variance estimates. Considered a priori confounders, multivariable models were adjusted for age as a continuous variable, monthly income and educational attainment as categorical variables; and sampling strategy (RDS vs. TLS). All analyses were conducting using SAS 9.4 (SAS Institute Inc., Cary, NC USA)

\section{Results}

\section{Relationship between gender identity, sex work and sociodemographic variables}

Of the 1077 participants recruited in Guatemala City, 13\% $(n=142)$ self-identified as transgender women and $87 \%(n=935)$ as cisgender men. Sex work in the past year was common among transgender women at $86 \%(n=122)$, whereas $30 \%(n=284)$ of cisgender male participants had received money for sex in the past 12 months and 70\% $(n=651)$ had not sold sex and were considered the referent. Among transgender women who did not receive money for sex in the past year $(n=20)$, $45 \%$ did so at some point during their lives.

Cisgender male sex workers were more likely to identify as heterosexual or bisexual (57.2\%) compared to cisgender male non-sex workers (34.6\%), who predominantly identified as gay (65.5\%). Transgender women and cisgender male sex workers had similar levels of education - most had completed at least some secondary education and few had any university education; non-sex workers were more likely to have a university education compared to transgender women and male sex workers (Table 1). Cisgender male sex workers had the lowest median monthly income (250 USD) while cisgender male non-sex workers had the highest (375 USD) and transgender women sex workers were in between (312 USD) (Table 1).

Table 1 . Demographics by exposure variable: transgender sex workers, cisgender male sex workers and cisgender male non-sex workers, Guatemala City.

\begin{tabular}{|c|c|c|c|c|}
\hline & $\begin{array}{l}\text { Transgender sex workers } \\
\text { a } \\
\text { (\%) }(n=122)\end{array}$ & $\begin{array}{l}\text { Male sex workers }{ }^{\mathrm{a}, \mathrm{b}} \\
\quad n(\%)(n=284)\end{array}$ & $\begin{array}{l}\text { Male non-sex workers }{ }^{\mathrm{b}} \\
\quad n(\%)(n=651)\end{array}$ & $p$-value \\
\hline \multicolumn{5}{|l|}{ Age } \\
\hline $18-24$ & $59(48.4)$ & $139(48.9)$ & $267(41.0)$ & \multirow[t]{3}{*}{0.17} \\
\hline $25-34$ & $43(35.2)$ & $101(35.6)$ & $257(39.5)$ & \\
\hline $35+$ & $20(16.4)$ & $44(15.5)$ & $127(19.5)$ & \\
\hline \multicolumn{5}{|l|}{ Education } \\
\hline primary or less & $31(25.4)$ & $78(27.5)$ & $42(6.5)$ & \multirow[t]{3}{*}{$<0.001$} \\
\hline some or completed secondary & $81(66.4)$ & $183(64.4)$ & $320(49.2)$ & \\
\hline some or completed university & $10(8.2)$ & $23(8.1)$ & $288(44.3)$ & \\
\hline \multicolumn{5}{|l|}{ Monthly income } \\
\hline$<\$ 300$ & $50(43.1)$ & $193(69.9)$ & $239(37.3)$ & \multirow[t]{4}{*}{$<0.001$} \\
\hline$\$ 300-500$ & $49(42.2)$ & $67(24.3)$ & $227(35.5)$ & \\
\hline$\$ 501-800$ & $11(9.5)$ & $11(4.0)$ & $87(13.6)$ & \\
\hline$>\$ 800$ & $6(5.2)$ & $5(1.8)$ & 87 (13.6) & \\
\hline \multicolumn{5}{|l|}{ Sexual orientation/gender identity } \\
\hline Heterosexual & $0(0.0)$ & $36(12.9)$ & $25(3.9)$ & \multirow[t]{4}{*}{$<0.001$} \\
\hline Bisexual & $0(0.0)$ & $124(44.3)$ & $199(30.7)$ & \\
\hline Gay & $0(0.0)$ & $120(42.9)$ & $425(65.5)$ & \\
\hline Transgender & $122(100.0)$ & $0(0.0)$ & $0(0.0)$ & \\
\hline
\end{tabular}




\section{Relationship between transgender identity, sex work, drug and alcohol use}

Transgender women sex workers were more likely to have used illicit drugs compared to cisgender male non-sex workers both in the bivariate and multivariate model after adjusting for age, income and education level ( $\mathrm{aPR}=2.7,95 \% \mathrm{CI}$ : 2.0, 3.5) (Table 2). Transgender women sex workers were also more likely to have used illicit drugs compared to cisgender male sex workers $(\mathrm{aPR}=1.2$, $95 \%$ CI: $0.9,1.6)$. Binge drinking was associated with identifying as a transgender woman sex worker vs. a cisgender male non-sex worker in bivariate and multivariate analyses ( $\mathrm{aPR}=1.6,95 \% \mathrm{CI}: 1.2$, 2.1). Male sex workers were twice as likely to use illicit drugs ( $\mathrm{aPR}=2.1,95 \% \mathrm{CI}: 1.7,2.8)$ and binge drink $(\mathrm{aPR}=1.6,95 \% \mathrm{CI}: 1.3,1.9)$ compared to cisgender male non-sex workers.

\section{Relationship between gender identity, sex work and adverse life events}

Transgender women sex workers as compared to non-sex worker cisgender men had higher risk for discrimination ( $\mathrm{aPR}=2.6,95 \% \mathrm{CI}: 2.2,3.2)$, being physically abused ( $\mathrm{aPR}=7.5,95 \% \mathrm{CI}: 4.4,12.7$ ) and being forced to have sex $(\mathrm{aPR}=7.5,95 \% \mathrm{CI}: 3.1,18.2)$ (Table 3). Additionally, transgender women sex workers when compared to cisgender male sex workers were more likely to be discriminated against in general ( $\mathrm{aPR}=2.0,95 \% \mathrm{CI}: 1.7,2.4)$, physically abused (aPR $=4.3,95 \% \mathrm{CI}: 2.7,6.9)$ and discriminated by family members ( $\mathrm{aPR}=1.8,95 \% \mathrm{CI}: 1.3,2.3)$. Transgender women sex workers were equally as likely as cisgender male sex workers to have experienced forced sex.

Table 2. Crude and adjusted analysis for drug and alcohol use as associated with transgender women sex workers compared to cisgender men who had not received money for sex and cisgender male sex workers.

\begin{tabular}{|c|c|c|c|c|c|c|c|c|c|c|}
\hline & \multicolumn{5}{|c|}{ Used illicit drugs $^{\mathrm{a}}$} & \multicolumn{5}{|c|}{ Binge drinking episode ${ }^{b}$} \\
\hline & $n(\%)$ & PR & $95 \% \mathrm{Cl}$ & $\mathrm{aPR}^{\mathrm{c}}$ & $95 \% \mathrm{Cl}$ & $n(\%)$ & PR & $95 \% \mathrm{Cl}$ & $\mathrm{aPR}^{\mathrm{c}}$ & $95 \% \mathrm{Cl}$ \\
\hline Transgender sex worker & $53(43.8)$ & 2.5 & $1.9,3.2$ & 2.7 & $2.0,3.5$ & $49(40.2)$ & 1.4 & $1.1,1.8$ & 1.6 & $1.2,2.1$ \\
\hline Male sex worker ${ }^{d}$ & $97(34.3)$ & 1.9 & $1.5,2.4$ & 2.1 & $1.7,2.8$ & $113(39.8)$ & 1.4 & $1.2,1.7$ & 1.6 & $1.3,1.9$ \\
\hline Male non- sex worker ${ }^{d}$ & $115(17.8)$ & 1 (ref) & & 1 (ref) & & $182(28.0)$ & 1 (ref) & & 1 (ref) & \\
\hline Transgender sex worker & $53(43.8)$ & 1.3 & $1.0,1.7$ & 1.2 & $0.9,1.6$ & $49(40.2)$ & 1.0 & $0.8,1.3$ & 1.0 & $0.8,1.3$ \\
\hline Male sex worker ${ }^{d}$ & $97(34.3)$ & 1 (ref) & & 1 (ref) & & $113(39.8)$ & 1 (ref) & & 1 (ref) & \\
\hline
\end{tabular}

PR Prevalence ratio; aPR adjusted prevalence ratio; $\mathrm{Cl}$ confidence intervals.

${ }^{\mathrm{a}}$ In the past 12 months.

b In the past 7 days.

cAdjusted for age, education and monthly income.

${ }^{d}$ All cisgender men included in the study reported sex with a transgender woman or a man in the past 12 months.

Table 3. Crude and adjusted analysis for mistreatment, forced sex and social exclusion as associated with transgender women sex workers compared to cisgender men who had not received money for sex and cisgender male sex workers.

Discriminated due to sexual identity ${ }^{\mathrm{a}}$

\begin{tabular}{|c|c|c|c|c|c|c|c|c|c|c|}
\hline & $n(\%)$ & PR & $95 \% \mathrm{Cl}$ & $a P R^{b}$ & $95 \% \mathrm{Cl}$ & $n(\%)$ & PR & $95 \% \mathrm{Cl}$ & $a P R^{b}$ & $95 \% \mathrm{Cl}$ \\
\hline Transgender sex worker & $89(73.0)$ & 2.9 & $2.4,3.4$ & 2.6 & $2.2,3.2$ & $55(45.1)$ & 1.3 & $1.0,1.6$ & 1.2 & $1.0,1.6$ \\
\hline Male sex worker ${ }^{c}$ & $110(38.7)$ & 1.5 & $1.3,1.9$ & 1.3 & $1.1,1.6$ & $71(25.2)$ & 0.7 & $0.6,0.9$ & 0.7 & $0.5,0.9$ \\
\hline Male non- sex worker ${ }^{c}$ & $165(25.3)$ & 1 (ref) & & 1 (ref) & & $225(34.8)$ & 1 (ref) & & 1 (ref) & \\
\hline Transgender sex worker & $89(73.0)$ & 1.9 & $1.6,2.3$ & 2.0 & $1.7,2.4$ & $55(45.1)$ & 1.8 & $1.4,2.4$ & 1.8 & $1.3,2.3$ \\
\hline Male sex worker ${ }^{c}$ & $110(38.7)$ & 1 (ref) & & 1 (ref) & & $71(25.2)$ & 1 (ref) & & 1 (ref) & \\
\hline & \multicolumn{5}{|c|}{ Physically abused $^{\mathrm{a}}$} & \multicolumn{5}{|c|}{ Forced to have sex ${ }^{a}$} \\
\hline Transgender sex worker & $35(28.7)$ & 9.3 & $5.6,15.6$ & 7.5 & $4.4,12.7$ & $15(13.5)$ & 6.5 & $3.0,14.2$ & 7.5 & $3.1,18.2$ \\
\hline Male sex worker ${ }^{c}$ & $25(8.8)$ & 2.9 & $1.6,5.1$ & 1.8 & $1.0,3.1$ & $28(12.5)$ & 6.0 & $3.0,12.2$ & 6.1 & $2.7,14.2$ \\
\hline Male non- sex worker & $20(3.1)$ & 1 (ref) & & 1 (ref) & & $10(2.1)$ & 1 (ref) & & 1 (ref) & \\
\hline Transgender sex worker & 35 (28.7) & 3.3 & $2.0,5.2$ & 4.3 & $2.7,6.9$ & $15(13.5)$ & 1.1 & $0.6,1.9$ & 1.2 & $0.7,2.3$ \\
\hline Male sex worker ${ }^{c}$ & $25(8.8)$ & 1 (ref) & & 1 (ref) & & $28(12.5)$ & 1 (ref) & & 1 (ref) & \\
\hline
\end{tabular}

PR Prevalence ratio; aPR adjusted prevalence ratio; $\mathrm{Cl}$ confidence intervals.

${ }^{a}$ In the past 12 months.

${ }^{\mathrm{b}}$ Adjusted for age, education and monthly income.

${ }^{c}$ All cisgender men included in the study reported sex with a transgender woman or a man in the past 12 months. 
Transgender women sex workers were two to three times as likely to experience at least two adverse life events when compared to cisgender male sex workers ( $\mathrm{aPR}=2.5,95 \% \mathrm{CI}$ : 1.9, 3.2) and cisgender male non-sex workers ( $\mathrm{aPR}=2.9,95 \% \mathrm{CI}: 2.3,3.8)$. Approximately $50 \%$ of transgender women sex workers had experienced two or more adverse life events compared to one quarter of cisgender male sex workers and approximately $15 \%$ of cisgender male non-sex workers. Cisgender male sex workers were also more likely to experience discrimination ( $\mathrm{aPR}=1.3,95 \% \mathrm{CI}: 1.1,1.6)$, physical abuse ( $\mathrm{aPR}=1.8,95 \% \mathrm{CI}: 1.0,3.1)$ and forced sex ( $\mathrm{aPR}=6.1,95 \% \mathrm{CI}: 2.7,14.2)$ compared to cisgender male non-sex workers.

\section{Discussion}

Sex work, current or past, was nearly ubiquitous among transgender women recruited for a behavioural survey in Guatemala City. Transgender women sex workers were more likely to face discrimination, physical abuse and forced sex compared to non-sex worker cisgender men. Moreover, transgender women sex workers and non-sex worker cisgender men were rejected by family more often than cisgender male sex workers. This is likely related to the fact that cisgender male sex workers identified more often as bisexual or heterosexual compared to non-sex worker men, probably hiding their sexual practices from family and friends and not assuming a non-conforming sexual orientation or gender identity. Cisgender male sex workers experienced physical violence and forced sex more often than cisgender male non-sex workers possibly due interactions with clients or visibility as street-based sex workers.

Illicit drug use and binge drinking was more common among transgender women sex workers and male sex workers than among non-sex worker cisgender men. Alcohol and drugs can serve as a coping mechanism to deal with minority status, the traumas of sex work or as part of a vicious cycle to feed addictions (Garland, Pettus-Davis, \& Howard, 2013; Rowe, Santos, McFarland, \& Wilson, 2015; Scheim, Bauer, \& Shokoohi, 2017). Regardless of the rationale, heavy use of illicit drugs and alcohol has been reported among transgender women in other countries and has been associated with HIV infection (Reback \& Fletcher, 2014; Reisner et al., 2016; Santos et al., 2014).

The combination of substance abuse, violence and discrimination that affects transgender women and male sex workers in Guatemala has been previously described as a syndemic (Brennan et al., 2012; Chakrapani, Newman, Shunmugam, Logie, \& Samuel, 2017; Mustanski, Garofalo, Herrick, \& Donenberg, 2007; Operario \& Nemoto, 2010). The term syndemic has been used to describe a set of enmeshed and mutually enhancing health problems that work together in a context of deleterious social and physical conditions to increase vulnerability (Singer, 2010). In Jamaica, a doseresponse relationship was found between the number of adverse life events and risk of HIV infection among transgender women, where adverse life events include ever having experienced physical violence, having been in jail, having been raped and having low literacy (Figueroa et al., 2015).

Similarly, transgender women sex workers and other people who face multiple or intersectional stigmas due to sexual orientation, gender identity, engagement in sex work, HIV infection or socioeconomic status is often referred to as intersectionality (Bowleg, 2012). The internalisation of multiple stigmas can generate feelings of shame, disability and guilt that lead to harmful behaviours and social vulnerability but can be overcome through self-acceptance, acceptance by family and friends, participation in peer and self-help groups and socio-political changes (Aristegui, Radusky, Zalazar, Lucas, \& Sued, 2018).

In Guatemala, a person who deviates from the traditional gender norms is an easy target for social exclusion as seen by the high prevalence of discrimination among transgender women compared to cisgender men presented in these findings. Discrimination can take the form of verbal harassment of street-based sex workers from passing cars to institutions refusal to call transgender women by their social name to hate crimes in the form of assault or murder (Aguilar Martinez \& Martinez, 2010; Tucker et al., 2014; Wheeler, Anfinson, Valvert, \& Lungo, 2014). Discrimination based on gender identity or sexual orientation acts as a risk factor for HIV, STI and mental health conditions 
when it leads to self-exclusion from society, fatalism or a barrier to accessing sexual health services (Logie et al., 2017).

The increased risk of verbal abuse, violence, forced sex and rejection experienced by transgender women sex workers in comparison to non-sex worker men this study are supported by quantitative and qualitative studies and news reports from Guatemala and other countries in the region (Aguilar Martinez et al., 2010; Aguilar Martinez \& Martinez, 2010; Evens et al., 2019; Wheeler et al., 2014). The discrimination faced by transgender women in Guatemala, Jamaica and Peru was explored in qualitative studies where participants expressed fear of discrimination related to gender identity, sexual behaviours and HIV/STI diagnosis as a barrier to accessing sexual health services and fear of rejection by peers for being diagnosed with HIV (Boyce et al., 2012; Logie et al., 2017; Perez-Brumer et al., 2017).

\section{Limitations}

The cross-sectional nature of this study makes it impossible to disentangle cause and effect in relation to adverse life events and engagement in sex work for MSM and transgender women in Guatemala. The questionnaire collected information on participants' sexual orientation and gender identity in one question conflating the two concepts. In hindsight and given current global guidelines on surveillance among transgender women, we would have assessed gender identity separately from sexual orientation using a two-step approach (WHO, et al., 2017). Hence, we may have misclassified transgender participants who did not identify as transgender/transsexual/transvestite and instead selected gay, bisexual or heterosexual as their sexual orientation. In this paper, men who have sex with transgender women but not cisgender men were labelled as men who have sex with men misgendering transgender women but keeping with the traditional use of the term MSM. Social desirability bias is a limitation of all behavioural surveys this one included, as participants may have hidden adverse life events or substance abuse considered shameful or unacceptable in society. Additionally, the combination of participants from two sampling strategies prevented us from using sampling weights in the analysis signifying that the results represent the participants and cannot be generalised to transgender women and MSM in Guatemala City.

\section{Conclusions}

Most bio-behavioural studies of MSM recruit transgender women as part of the sample but do not always disaggregate the results based on gender identity or engagement in sex work. We found major differences in individual and societal risk factors when disaggregating by gender and sex work, evidence that future collection and reporting data for different populations such as transgender women and male cisgender sex workers would allow the research and public health community better understand the diversity of risk among people who traditionally fell under the MSMumbrella term.

Given the available research on HIV risk, transgender women and male cisgender sex workers would benefit from prevention interventions tailored to their needs (Ma et al., 2007; Oster et al., 2014; van Griensven et al., 2010; Wang et al., 2014; Zhong et al., 2014). Transgender women and cisgender male sex workers in Guatemala and other similar contexts would benefit from harm reduction for substance use, violence prevention and response and strategies to mitigate discrimination, such a support networks, to address underlying determinants of HIV infection (Aristegui et al., 2018; Pollock et al., 2016; Tucker et al., 2014). Mass media campaigns that sensitise and educate the general population on gender and sexual diversity would help reduce social stigma and discrimination towards people of diverse sexual and gender identities (Creel, Rimal, Mkandawire, Bose, \& Brown, 2011; Fakolade, Adebayo, Anyanti, \& Ankomah, 2010; Kerr et al., 2015). 


\section{Acknowledgments}

The authors thank institutions and venue owners involved in the implementation of this study. The authors recognise the contribution of the field staff and technical consultants: Berta Alvarez, Nelson Arambú, Flor de María Hernández, José Manuel Aguilar, Sabrina Boyce, Andres Alvarado, Sonia Morales Miranda, Jessica España, Norma Zúniga, César Galindo and Andrea Kim. The authors are also grateful for the two anonymous reviewers' valuable comments that greatly improved the manuscript.

\section{Data availability statement}

The data are not available online or to the public. Data availability was not contemplated at the time the study was approved by ethics committees and funders. Given the stigma associated with transgender and sexual minorities in Guatemala, making the data public could exposure the participants to increased stigma and discrimination, especially for a small population such as transgender women in Guatemala City.

\section{Disclosure statement}

No potential conflict of interest was reported by the authors.

\section{Funding}

This study was carried out in collaboration with Tephinet Inc. and the HIV Unit of the Center of Health Studies from the Universidad del Valle de Guatemala and supported by the U.S. President's Emergency Plan for AIDS Relief (PEPFAR) through the U.S. Centers for Disease Control and Prevention (CDC), under the terms of Cooperative Agreements SD43GH000014-05 and GH0000575. The findings and conclusions in this report are those of the authors and do not necessarily represent the official position of the U.S. Centers for Disease Control and Prevention.

\section{ORCID}

William M. Miller (D) http://orcid.org/0000-0002-4140-1797

\section{References}

Aguilar Martinez, J. M., Castillo, A., de Ramirez, A. L., \& Reynoso, N. A. (2010). Estudio diagnóstico sobre percepción y situación de los derechos humanos en la diversidad sexual de Guatemala en los departamentos de Suchitepéquez, Retalhuleu, Quetzaltenango, San Marcos y Petén. Guatemala City: Colectivo de Amigos contra el Sida (CAS).

Aguilar Martinez, J. M., \& Martinez, J. (2010). Crimenes de odio en Guatemala (Study Report No. Guatemala City).

Amnesty International. (2001). Crimes of hate, conspiracy of silence: Crimes of hate, conspiracy of silence ACT 40/016/ 2001. London: T. A. Press.

Aristegui, I., Radusky, P. D., Zalazar, V., Lucas, M., \& Sued, O. (2018). Resources to cope with stigma related to HIV status, gender identity, and sexual orientation in gay men and transgender women. Journal of Health Psychology, 23 (2), 320-331. doi:10.1177/1359105317736782. Retrieved from https://www.ncbi.nlm.nih.gov/pubmed/29069922

Baggaley, R. F., White, R. G., \& Boily, M. C. (2010). HIV transmission risk through anal intercourse: Systematic review, meta-analysis and implications for HIV prevention. International Journal of Epidemiology, 39(4), $1048-1063$. doi:10.1093/ije/dyq057

Baral, S. D., Friedman, M. R., Geibel, S., Rebe, K., Bozhinov, B., Diouf, D., ... Caceres, C. F. (2015). Male sex workers: Practices, contexts, and vulnerabilities for HIV acquisition and transmission. Lancet, 385(9964), 260-273. doi:10. 1016/S0140-6736(14)60801-1. Retrieved from https://www.ncbi.nlm.nih.gov/pubmed/25059939

Baral, S., Logie, C. H., Grosso, A., Wirtz, A. L., \& Beyrer, C. (2013). Modified social ecological model: A tool to guide the assessment of the risks and risk contexts of HIV epidemics. BMC Public Health, 13, 482. doi:10.1186/1471-245813-482. Retrieved from http://www.ncbi.nlm.nih.gov/pubmed/23679953

Baral, S. D., Poteat, T., Stromdahl, S., Wirtz, A. L., Guadamuz, T. E., \& Beyrer, C. (2013). Worldwide burden of HIV in transgender women: A systematic review and meta-analysis. The Lancet Infectious Diseases, 13(3), 214-222. doi:10. 1016/S1473-3099(12)70315-8. Retrieved from http://www.ncbi.nlm.nih.gov/pubmed/23260128 
Baral, S., Sifakis, F., Cleghorn, F., \& Beyrer, C. (2007). Elevated risk for HIV infection among men who have sex with men in low- and middle-income countries 2000-2006: A systematic review. PLoS Medicine, 4(12), e339. doi:07PLME-RA-1077 [pii]. doi:10.1371/journal.pmed.0040339

Barrington, C., Acevedo, R., Donastorg, Y., Perez, M., \& Kerrigan, D. (2017). 'HIV and work don't go together': Employment as a social determinant of HIV outcomes among men who have sex with men and transgender women in the Dominican Republic. Global Public Health, 12(12), 1506-1521. doi:10.1080/17441692.2016. 1160141. Retrieved from https://www.ncbi.nlm.nih.gov/pubmed/26999251

Barrington, C., Galindo Arandi, C., Aguilar-Martínez, J. M., \& Miller, W. M. (2018). Understanding HIV disparities among transgender women in Guatemala: Linking social and structural factors to HIV vulnerability. In D. Kerrigan, \& C. Barrington (Eds.), Structural Dynamics of HIV: Risk, Resilience and response (pp. 3-17). Cham: Springer International Publishing.

Barrington, C., Wejnert, C., Guardado, M. E., Nieto, A. I., \& Bailey, G. P. (2012). Social network characteristics and HIV vulnerability among transgender persons in San Salvador: Identifying opportunities for HIV prevention strategies. AIDS and Behavior, 16(1), 214-224. doi:10.1007/s10461-011-9959-1

Bauer, G. R., Travers, R., Scanlon, K., \& Coleman, T. A. (2012). High heterogeneity of HIV-related sexual risk among transgender people in Ontario, Canada: A province-wide respondent-driven sampling survey. BMC Public Health, 12, 292. doi:10.1186/1471-2458-12-292

Beyrer, C., Baral, S. D., van Griensven, F., Goodreau, S. M., Chariyalertsak, S., Wirtz, A. L., \& Brookmeyer, R. (2012). Global epidemiology of HIV infection in men who have sex with men. Lancet, 380(9839), 367-377. doi:10.1016/ s0140-6736(12)60821-6

Bith-Melander, P., Sheoran, B., Sheth, L., Bermudez, C., Drone, J., Wood, W., \& Schroeder, K. (2010). Understanding sociocultural and psychological factors affecting transgender people of color in San Francisco. Journal of the Association of Nurses in AIDS Care, 21(3), 207-220. doi:10.1016/j.jana.2010.01.008

Bockting, W. O., Robinson, B. E., \& Rosser, B. R. (1998). Transgender HIV prevention: A qualitative needs assessment. AIDS Care, 10(4), 505-525. doi:10.1080/09540129850124028

Bowleg, L. (2012). The problem with the phrase women and minorities: Intersectionality-an important theoretical framework for public health. American Journal of Public Health, 102(7), 1267-1273. doi:10.2105/AJPH.2012.300750. Retrieved from https:/www.ncbi.nlm.nih.gov/pubmed/22594719

Boyce, S., Barrington, C., Bolanos, H., Arandi, C. G., \& Paz-Bailey, G. (2012). Facilitating access to sexual health services for men who have sex with men and male-to-female transgender persons in Guatemala City. Culture, Health \& Sexuality, 14(3), 313-327. doi:10.1080/13691058.2011.639393

Brennan, J., Kuhns, L. M., Johnson, A. K., Belzer, M., Wilson, E. C., \& Garofalo, R. (2012). Syndemic theory and HIVrelated risk among young transgender women: The role of multiple, Co-Occurring health problems and social marginalization. American Journal of Public Health, 102(9), 1751-1757. doi:10.2105/ajph.2011.300433

Chakrapani, V., Newman, P. A., Shunmugam, M., Logie, C. H., \& Samuel, M. (2017). Syndemics of depression, alcohol use, and victimisation, and their association with HIV-related sexual risk among men who have sex with men and transgender women in India. Global Public Health, 12(2), 250-265. doi:10.1080/17441692.2015.1091024. Retrieved from http://www.ncbi.nlm.nih.gov/pubmed/26457339

Clements-Nolle, K., Marx, R., Guzman, R., \& Katz, M. (2001). HIV prevalence, risk behaviors, health care use, and mental health status of transgender persons: Implications for public health intervention. American Journal of Public Health, 91(6), 915-921.

Clements-Nolle, K., Marx, R., \& Katz, M. (2006). Attempted suicide among transgender persons: The influence of gender-based discrimination and victimization. Journal of Homosexuality, 51(3), 53-69. doi:10.1300/J082v51n03_04

Creel, A. H., Rimal, R. N., Mkandawire, G., Bose, K., \& Brown, J. W. (2011). Effects of a mass media intervention on HIV-related stigma: 'radio Diaries' program in Malawi. Health Education Research, 26(3), 456-465. doi:10.1093/ her/cyr012. Retrieved from https://www.ncbi.nlm.nih.gov/pubmed/21393376

Creswell, J., Guardado, M. E., Lee, J., Nieto, A. I., Kim, A. A., Monterroso, E., \& Paz-Bailey, G. (2012). HIV and STI control in El Salvador: Results from an integrated behavioural survey among men who have sex with men. Sexually Transmitted Infections, 88(8), 633-638. doi:10.1136/sextrans-2012-050521. Retrieved from https://www.ncbi.nlm. nih.gov/pubmed/22917694

Dean, L., White, J., Dunn, P., Lawrence, A., Wolfe, D., Xavier, J., ... Rothblum, E. (2000). Lesbian, Gay, bisexual, and transgender health: Findings and concerns. Journal of the Gay and Lesbian Medical Association, 4(3), $102-151$. doi:10.1023/a:1009573800168. Retrieved from http://unc.summon.serialssolutions.com/link/0/eLvHCXMwY2BQs DRMNbdMMUszNE9JNTUxSjRKNjBIMkqzADY2Uo2TLUAbk8OcjH28zV2dTEKQSnM3UQZdN9cQZw9d2Jx kfAHkyAXQZYngyVID83iTeON4I9AWbINDMQYWYB85la8u2O-74Hnfmv4V141dbn1eBQBHnCUR

Evens, E., Lanham, M., Santi, K., Cooke, J., Ridgeway, K., Morales, G., ... Dayton, R. (2019). Experiences of genderbased violence among female sex workers, men who have sex with men, and transgender women in Latin America and the Caribbean: A qualitative study to inform HIV programming. BMC International Health and Human Rights, 19(1), 9. doi:10.1186/s12914-019-0187-5. Retrieved from https:/www.ncbi.nlm.nih.gov/pubmed/ 30832664 
Fakolade, R., Adebayo, S. B., Anyanti, J., \& Ankomah, A. (2010). The impact of exposure to mass media campaigns and social support on levels and trends of HIV-related stigma and discrimination in Nigeria: Tools for enhancing effective HIV prevention programmes. Journal of Biosocial Science, 42(3), 395-407. doi:10.1017/S0021932009990538. Retrieved from https://www.ncbi.nlm.nih.gov/pubmed/20018118

Figueroa, J. P., Cooper, C. J., Edwards, J. K., Byfield, L., Eastman, S., Hobbs, M. M., ... Caylà, J. A. (2015). Understanding the high prevalence of HIV and other sexually transmitted infections among socio-economically vulnerable men who have sex with men in Jamaica. PLoS One, 10(2), e0117686. doi:10.1371/journal.pone. 0117686 Retrieved from http://www.ncbi.nlm.nih.gov/pubmed/25659122

Galindo Arandi, C. (2010). Caligrafia de la memoria: Historias en cuerpos que se leen (Study report No.) Guatemala City.

Garland, E. L., Pettus-Davis, C., \& Howard, M. O. (2013). Self-medication among traumatized youth: Structural equation modeling of pathways between trauma history, substance misuse, and psychological distress. Journal of Behavioral Medicine, 36(2), 175-185. doi:10.1007/s10865-012-9413-5. Retrieved from https://www.ncbi.nlm.nih. gov/pubmed/22454227

Garofalo, R., Herrick, A., Mustanski, B. S., \& Donenberg, G. R. (2007). Tip of the Iceberg: Young men who have sex with men, the internet, and HIV risk. American Journal of Public Health, 97(6), 1113-1117. doi:10.2105/ajph.2005. 075630

Garofalo, R., Osmer, E., Sullivan, C., Doll, M., \& Harper, G. (2006). Environmental, psychosocial, and individual correlates of HIV risk in ethnic minority male-to-female transgender youth. Journal of HIV/AIDS Prevention in Children \& Youth, 7(2), 89-104. Retrieved from. http://unc.summon.serialssolutions.com/link/0/ eLvHCXMwTV2xCsIwEA3i4OJS0Kz-QMr1mpje2tIiWJyKqFuaJmNBrf9vUhUc33TL8d4b7t1jbOesIe 0sYB-8tg3kZzQYiVqrzGPuYm74XObtUdel7P7YvEnYwo0b1jV1Vx3EtwxAWEIlfBASoqD2hpT2qJB6GWOlsdL D22A7yCnAwSkTf-8OhVIFgfUEMNBeg8y2bG3izfg4zdmygbP19Hg5HjmXh_mcrS5UXU-3tvnA5AfT55x_Su8T DxQ_r4fAFN51-je-

Guadamuz, T. E., Wimonsate, W., Varangrat, A., Phanuphak, P., Jommaroeng, R., McNicholl, J. M., ... van Griensven, F. (2011). HIV prevalence, risk behavior, hormone use and surgical history among transgender persons in Thailand. AIDS and Behavior, 15(3), 650-658. doi:10.1007/s10461-010-9850-5

Kenagy, G. P. (2005). Transgender health: Findings from two needs assessment studies in Philadelphia. Health \& Social Work, 30(1), 19-26.

Kerr, J. C., Valois, R. F., DiClemente, R. J., Carey, M. P., Stanton, B., Romer, D., ... Fortune, T. (2015). The effects of a mass media HIV-risk reduction strategy on HIV-related stigma and knowledge among African American adolescents. AIDS Patient Care and STDs, 29(3), 150-156. doi:10.1089/apc.2014.0207. Retrieved from https://www.ncbi. nlm.nih.gov/pubmed/25738952

Kim, A. A., Morales, S., Lorenzana de Rivera, I., Paredes, M., Juarez, S., Alvarez, B., ... Paz-Bailey, G. (2013). Short communication: HIV incidence among vulnerable populations in Honduras: Results from an integrated behavioral and biological survey among female sex workers, men who have sex with men, and Garifuna in Honduras, 2006. AIDS Research and Human Retroviruses, 29(3), 516-519. doi:10.1089/AID.2012.0032. Retrieved from https://www. ncbi.nlm.nih.gov/pubmed/23034068

Koken, J. A., Bimbi, D. S., \& Parsons, J. T. (2009). Experiences of familial acceptance-rejection among transwomen of color. Journal of Family Psychology, 23(6), 853-860. doi:10.1037/a0017198. Retrieved from https://www.ncbi.nlm. nih.gov/pubmed/20001144

Logie, C. H., Lacombe-Duncan, A., Brien, N., Jones, N., Lee-Foon, N., Levermore, K., ... Newman, P. A. (2017). Barriers and facilitators to HIV testing among young men who have sex with men and transgender women in Kingston, Jamaica: A qualitative study. Journal of the International AIDS Society, 20(1), 21385. doi:10.7448/IAS. 20.1.21385. Retrieved from https://www.ncbi.nlm.nih.gov/pubmed/28406274

Lombardi, E. L., Wilchins, R. A., Priesing, D., \& Malouf, D. (2001). Gender violence: Transgender experiences with violence and discrimination. Journal of Homosexuality, 42(1), 89-101.

Ma, X., Zhang, Q., He, X., Sun, W., Yue, H., Chen, S., ... McFarland, W. (2007). Trends in prevalence of HIV, syphilis, hepatitis $\mathrm{C}$, hepatitis $\mathrm{B}$, and sexual risk behavior among men who have sex with men. Results of 3 consecutive respondent-driven sampling surveys in Beijing, 2004 through 2006. JAIDS Journal of Acquired Immune Deficiency Syndromes, 45(5), 581-587. doi:10.1097/QAI.0b013e31811eadbc. Retrieved from http://www.ncbi.nlm. nih.gov/pubmed/17577125

Mansergh, G., Shouse, R. L., Marks, G., Guzman, R., Rader, M., Buchbinder, S., \& Colfax, G. N. (2006). Methamphetamine and sildenafil (Viagra) use are linked to unprotected receptive and insertive anal sex, respectively, in a sample of men who have sex with men. Sexually Transmitted Infections, 82(2), 131-134. doi:10.1136/sti. 2005.017129

Melendez, R. M., \& Pinto, R. (2007). 'It's really a hard life': Love, gender and HIV risk among male-to-female transgender persons. Culture, Health \& Sexuality, 9(3), 233-245. doi:10.1080/13691050601065909

Morales-Miranda, S., Álvarez-Rodríguez, B., Arambú, N., Aguilar-Martínez, J., Huamán Zevallos, B., Figueroa, W., ... Castillo, A. (2013). Encuesta de Vigilancia de Comportamiento Sexual y Prevalencia del VIH e ITS, en poblaciones vulnerables y poblaciones clave. (Publicacion UVG No. 27). Guatemala. 
Mustanski, B., Garofalo, R., Herrick, A., \& Donenberg, G. (2007). Psychosocial health problems increase risk for HIV among urban young men who have sex with men: Preliminary evidence of a syndemic in need of attention. Annals of Behavioral Medicine, 34(1), 37-45. doi:10.1080/08836610701495268

Nemoto, T., Operario, D., Keatley, J., Han, L., \& Soma, T. (2004). HIV risk behaviors among male-to-female transgender persons of color in San Francisco. American Journal of Public Health, 94(7), 1193-1199.

Nemoto, T., Sausa, L. A., Operario, D., \& Keatley, J. (2006). Need for HIV/AIDS education and intervention for MTF transgenders: Responding to the challenge. Journal of Homosexuality, 51(1), 183-202. doi:10.1300/J082v51n01_09

Nuttbrock, L., Bockting, W., Rosenblum, A., Hwahng, S., Mason, M., Macri, M., \& Becker, J. (2013). Gender abuse, depressive symptoms, and HIV and other sexually transmitted infections among male-to-female transgender persons: A three-year prospective study. American Journal of Public Health, 103(2), 300-307. doi:10.2105/AJPH.2011. 300568. Retrieved from http://www.ncbi.nlm.nih.gov/pubmed/22698023

Nuttbrock, L., Hwahng, S., Bockting, W., Rosenblum, A., Mason, M., Macri, M., \& Becker, J. (2009). Lifetime risk factors for HIV/sexually transmitted infections among male-to-female transgender persons. JAIDS Journal of Acquired Immune Deficiency Syndromes, 52(3), 417-421. doi:10.1097/QAI.0b013e3181ab6ed8

Operario, D., \& Nemoto, T. (2010). HIV in transgender communities: Syndemic dynamics and a need for multicomponent interventions. JAIDS Journal of Acquired Immune Deficiency Syndromes, 55(Suppl 2), S91-S93. doi:10.1097/ QAI.0b013e3181fbc9ec

Operario, D., Soma, T., \& Underhill, K. (2008). Sex work and HIV status among transgender women: Systematic review and meta-analysis. JAIDS Journal of Acquired Immune Deficiency Syndromes, 48(1), 97-103. doi:10.1097/ QAI.0b013e31816e3971

Oster, A. M., Johnson, C. H., Le, B. C., Balaji, A. B., Finlayson, T. J., Lansky, A., ... Paz-Bailey, G. (2014). Trends in HIV prevalence and HIV testing among young MSM: Five United States cities, 1994-2011. AIDS and Behavior, 18(Suppl 3), S237-S247. doi:10.1007/s10461-013-0566-1. Retrieved from http://www.ncbi.nlm.nih.gov/pubmed/23955658

Parker, R., \& Aggleton, P. (2003). HIV and AIDS-related stigma and discrimination: A conceptual framework and implications for action. Social Science \& Medicine, 57(1), 13-24. Retrieved from http://www.ncbi.nlm.nih.gov/ pubmed/12753813.

Paz-Bailey, G., Miller, W., Shiraishi, R. W., Jacobson, J. O., Abimbola, T. O., \& Chen, S. Y. (2013). Reaching men who have sex with men: A comparison of respondent-driven sampling and time-location sampling in Guatemala City. AIDS and Behavior, 17(9), 3081-3090. doi:10.1007/s10461-013-0589-7

Perez-Brumer, A. G., Reisner, S. L., McLean, S. A., Silva-Santisteban, A., Huerta, L., Mayer, K. H., ... Lama, J. R. (2017). Leveraging social capital: Multilevel stigma, associated HIV vulnerabilities, and social resilience strategies among transgender women in Lima, Peru. Journal of The international Aids Society, 20(1), 1-8. doi:10.7448/IAS.20.1. 21462. Retrieved from http://www.ncbi.nlm.nih.gov/pubmed/28362064

Pollock, L., Silva-Santisteban, A., Sevelius, J., \& Salazar, X. (2016). 'You should build yourself up as a whole product': Transgender female identity in Lima, Peru. Global Public Health, 11(7-8), 981-993. doi:10.1080/17441692.2016. 1167932. Retrieved from https://www.ncbi.nlm.nih.gov/pubmed/27080150

Poteat, T., Reisner, S. L., \& Radix, A. (2014). HIV epidemics among transgender women. Current Opinion in HIV and AIDS, 9(2), 168-173. doi:10.1097/coh.0000000000000030

Prestage, G., Jin, F., Kippax, S., Zablotska, I., Imrie, J., \& Grulich, A. (2009). Use of illicit drugs and erectile dysfunction medications and subsequent HIV infection among gay men in Sydney, Australia. The Journal of Sexual Medicine, 6 (8), 2311-2320. doi:10.1111/j.1743-6109.2009.01323.x

Reback, C. J., \& Fletcher, J. B. (2014). HIV prevalence, substance use, and sexual risk behaviors among transgender women recruited through outreach. AIDS and Behavior, 18(7), 1359-1367. doi:10.1007/s10461-013-0657-z. Retrieved from http://www.ncbi.nlm.nih.gov/pubmed/24287786

Reisner, S. L., Poteat, T., Keatley, J., Cabral, M., Mothopeng, T., Dunham, E., ... Baral, S. D. (2016). Global health burden and needs of transgender populations: A review. Lancet, 388(10042), 412-436. doi:10.1016/S0140-6736 (16)00684-X. Retrieved from http://www.ncbi.nlm.nih.gov/pubmed/27323919

Rowe, C., Santos, G. M., McFarland, W., \& Wilson, E. C. (2015). Prevalence and correlates of substance use among trans female youth ages 16-24 years in the San Francisco Bay Area. Drug and Alcohol Dependence, 147, 160166. doi:10.1016/j.drugalcdep.2014.11.023. Retrieved from https://www.ncbi.nlm.nih.gov/pubmed/25548025

Santos, G. M., Rapues, J., Wilson, E. C., Macias, O., Packer, T., Colfax, G., \& Raymond, H. F. (2014). Alcohol and substance use among transgender women in San Francisco: Prevalence and association with human immunodeficiency virus infection. Drug and Alcohol Review. doi:10.1111/dar.12116. Retrieved from http://www.ncbi.nlm.nih.gov/ pubmed/24628655

Scheim, A. I., Bauer, G. R., \& Shokoohi, M. (2017). Drug use among transgender people in Ontario, Canada: Disparities and associations with social exclusion. Addictive Behaviors, 72, 151-158. doi:10.1016/j.addbeh.2017.03.022. Retrieved from https://www.ncbi.nlm.nih.gov/pubmed/28411424

Singer, M. (2010). Pathogen-pathogen interaction: A syndemic model of complex biosocial processes in disease. Virulence, 1(1), 10-18. doi:10.4161/viru.1.1.9933

Stieglitz, K. A. (2010). Development, risk, and resilience of transgender youth. Journal of the Association of Nurses in AIDS Care, 21(3), 192-206. doi:10.1016/j.jana.2009.08.004 
Tucker, C., Arandi, C. G., Bolanos, J. H., Paz-Bailey, G., \& Barrington, C. (2014). Understanding social and sexual networks of sexual minority men and transgender women in Guatemala city to improve HIV prevention efforts. Journal of Health Care for the Poor and Underserved, 25(4), 1698-1717. doi:10.1353/hpu.2014.0163. Retrieved from https://www.ncbi.nlm.nih.gov/pubmed/25418236

UNAIDS. (2008). A framework for monitoring and evaluating HIV prevention programmes for most-at-risk populations. Geneva: UNAIDS.

UNAIDS \& WHO. (2011). Guidelines on surveillance among populations most at risk for HIV. Geneva: World Health Organization.

van Griensven, F., Varangrat, A., Wimonsate, W., Tanpradech, S., Kladsawad, K., Chemnasiri, T., ... Plipat, T. (2010). Trends in HIV prevalence, estimated HIV incidence, and risk behavior among men who have sex with men in Bangkok, Thailand, 2003-2007. JAIDS Journal of Acquired Immune Deficiency Syndromes, 53(2), $234-239$. doi:10.1097/QAI.0b013e3181c2fc86. Retrieved from http://www.ncbi.nlm.nih.gov/pubmed/19901844

Wang, X., Lan, G., Shen, Z., Vermund, S. H., Zhu, Q., Chen, Y., ... Tang, Z. (2014). HIV and syphilis prevalence trends among men who have sex with men in Guangxi, China: Yearly cross-sectional surveys, 2008-2012. BMC Infectious Diseases, 14(1), 367. doi:10.1186/1471-2334-14-367. Retrieved from http://www.ncbi.nlm.nih.gov/pubmed/ 24993252

Wheeler, J., Anfinson, K., Valvert, D., \& Lungo, S. (2014). Is violence associated with increased risk behavior among MSM? Evidence from a population-based survey conducted across nine cities in Central America. Global Health Action, 7, 24814. doi:10.3402/gha.v7.24814. Retrieved from http://www.ncbi.nlm.nih.gov/pubmed/25361722

WHO. (2011). Prevention and treatment of HIV and other sexually transmitted infections among men who have sex with men and transgender people: Recommendations for a public health approach. Geneva: World Health Organization.

WHO. (2015). Consolidated strategic information guidelines for HIV in the health sector. Geneva: World Health Organization.

WHO, CDC, UNAIDS, \& FHI 360. (2017). Biobehavioural survey guidelines for populations at risk for HIV. Geneva: World Health Organization.

Wong, W., Chaw, J. K., Kent, C. K., \& Klausner, J. D. (2005). Risk factors for early syphilis among gay and bisexual men seen in an STD clinic: San Francisco, 2002-2003. Sexually Transmitted Diseases, 32(7), 458-463.

Zhong, F., Liang, B., Xu, H., Cheng, W., Fan, L., Han, Z., ... Ling, L. (2014). Increasing HIV and decreasing syphilis prevalence in a context of persistently high unprotected anal intercourse, six consecutive annual surveys among men who have sex with men in Guangzhou, China, 2008 to 2013. PLoS One, 9(7), e103136. doi:10.1371/journal. pone.0103136. Retrieved from http://www.ncbi.nlm.nih.gov/pubmed/25061936 